\title{
The Stability Analysis and Optimization Design of the West Side Final Slope of Bu-Zhao-Ba
}

\author{
Shiguo Sun 1,a , Zizhen Miao ${ }^{2,}$ and Yujuan Zhang ${ }^{3, c}$ \\ 1,2,3No.5 Jin Yuan Zhuang Road, Shi Jing Shan District, Beijing, China \\ assg981@163.com, b406818699@qq.com, c1150623253@qq.com
}

\begin{abstract}
Keywords: Final slope; Critical sliding field technology; Slope stability; Optimization design
Abstract: Aiming at the problem of the west side final slope stability of Bu-Zhao-Ba, at first, based on the critical sliding field technology, the most dangerous landslide slip surface is searched and identified, and then, the final slope stability of the 342 section is analyzed though various limit equilibrium methods, some feasible slope treatment projects is proposed. And last, we get the optimal treatment scheme through comparative analysis, which not only ensures the slope safety but also maximize the economic benefit.
\end{abstract}

\section{Introduction}

Xiao-Long-Tan Bu-Zhao-Ba open-pit mine in Yunnan province is a national large open-pit coal mine, which produces 5 million tons of coal every year. Along with the mining, the slope has different degree of deformation and failure, which not only seriously affect the safety of mine own and also cause a severe threat to the safety of the ground buildings and the surrounding environment. The stability of open-pit slope has become a controlling factor which influences the mine production safety. At present, the west side slope is entering into the final mining stage, the stability analysis and control measures of final slope has become a serious problem. Therefore, based on the critical sliding field technology, the most dangerous landslide slip surface is searched and identified, and, the final slope stability of the 342 section is analyzed though various limit equilibrium methods, some feasible slope treatment projects is proposed afterwards. Finally, taking the degree of difficulty of project implementation, applicability, economy into consideration, we obtain the optimal countermeasure which not only ensures the slope safety but also maximize the economic benefit, can meet the natural resources requirements of Yunnan province economic development.

\section{Brief Introduction of Critical Sliding Field Technology}

The critical sliding field technology can quickly and accurately identify critical slip surfaces of slope in any shape. The slip surface searched by the critical sliding field technology is also more conform to the actual situation ${ }^{[1]}$. It, based on the theory of the limit equilibrium slice method, divide the slope into many strips first, then divide the strips into many state points. Under the condition of given safety factor, the strength of the slope body is mobilized by the same proportion. The dangerous sliding direction which is represented by $\tan \alpha, \alpha$ is the dip of the slip surface that go through the point, and the most unfavorable thrust (P) are present in any point on the strip sideline which is not limited to the state of point, and they make the residual thrust maximum at final exit. Tan $\alpha$, P approximately show piecewise linear distribution along the strip sideline ${ }^{[2]}$. For specific strip, only considering the force balance, the direction of the force between strips $(\theta)$ is considered in accordance with the conventional slice method. According to the force balance of the strips as shown in Fig. 1, the thrust is calculated by Eq. 1.

$$
\begin{aligned}
P_{\mathrm{i}} & =\frac{\cos \left(\alpha_{\mathrm{i}}-\theta_{i-1}-\bar{\varphi}_{\mathrm{i}}\right) P_{\mathrm{i}-1}+\cos \left(\alpha_{\mathrm{i}}-\beta_{0}-\bar{\varphi}_{\mathrm{i}}\right) W_{\mathrm{i}} \sqrt{1+K_{0}^{2}}+u_{\mathrm{i}} l_{\mathrm{i}} \sin \bar{\varphi}_{\mathrm{i}}-\bar{c}_{\mathrm{i}} l_{\mathrm{i}} \cos \bar{\varphi}_{\mathrm{i}}}{\cos \left(\alpha_{\mathrm{i}}-\theta_{\mathrm{i}}-\bar{\varphi}_{\mathrm{i}}\right)} \\
\beta_{0} & =\arctan \left(1 / K_{0}\right) \\
\bar{\varphi}_{\mathrm{i}} & =\arctan ^{-1}\left(\tan \varphi_{\mathrm{i}} / F_{s}\right)
\end{aligned}
$$




$$
\begin{aligned}
\overline{c_{\mathrm{l}}} & =c_{i} / F_{s} \\
P_{i+1} & =\frac{\cos \left(a_{i+1}-\theta_{i}-\bar{\varphi}_{i+1}\right)}{\cos \left(a_{i+1}-\theta_{i+1}-\bar{\varphi}_{i+1}\right)} P_{i}+g_{i+1}
\end{aligned}
$$
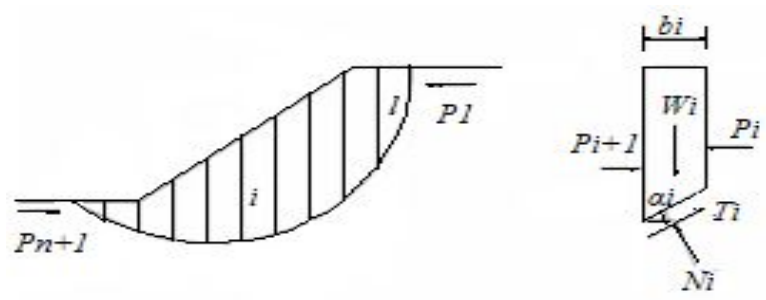

Fig.1 Force balance of the strips

$P_{i-1}, P_{i}, P_{i+1}$ is thrust between strips, $F_{s}$ is the given safety factor, $K_{0}$ is the seismic influence coefficient, $W_{i}$ represents the strip's weight, $c_{i}$ is the cohesion of the strip bottom, $\varphi_{\mathrm{i}}$ is the internal friction angle, $\mathrm{u}_{\mathrm{i}}$ is the pore water pressure of the strip bottom, $\mathrm{l}_{\mathrm{i}}$ is the side length of the strip bottom, $\alpha_{i}$ and $\alpha_{i-1}$ is the angle of inclination of the current strip and the upper strip, $g_{i+1}$ is the constant related to the strip $i+1$.

Critical sliding field technology's departure point as follows: firstly, based on the given safety factor, the most dangerous sliding direction $(\tan \alpha)$ of each state point is in turn worked out to let the final thrust maximum. Then change the safety factor, let the maximum residual thrust to zero, finally, achieve the dangerous sliding direction field in the critical state, furtherly track out the continuous critical sliding field ${ }^{[3]}$.

\section{Stability Analysis and Optimal Design of the Final Slope on the 342 Section}

\subsection{Project Overview}

$\mathrm{Bu}-\mathrm{Zhao}-\mathrm{Ba}$ mine is an oval rift basin, Nan-Pan river from west to east pass through the basin, which result the basin is divided into two parts - north and south. Basin area of $18 \mathrm{~km}^{2}$, bearing area of $9103 \mathrm{~km}^{2}$, the surrounding mountain elevation of $1499 \sim 1966 \mathrm{~m}$, basin elevation $1039 \sim$ $1200 \mathrm{~m}$, open pit lowermost elevation of $977 \mathrm{~m}$.

Surrounding basin and the bottom is comprised of the triassic limestones. Tertiary and quaternary stratigraphy compose the basin stratigraphy, the neogene pliocene riverhead coal group is comprised of claystone, silty clay and inferior coal. Xiao-Long-Tan miocene coal consists of mudstone, coal, carbonaceous claystone and claystone. The quaternary loose soil consists of fluvial and eluvial cohesive soil and gravel. Fig. 2 shows the slope contour line and the rock layer distribution on the 342 section. The geotechnical layer mechanical parameter is shown in Table 1.

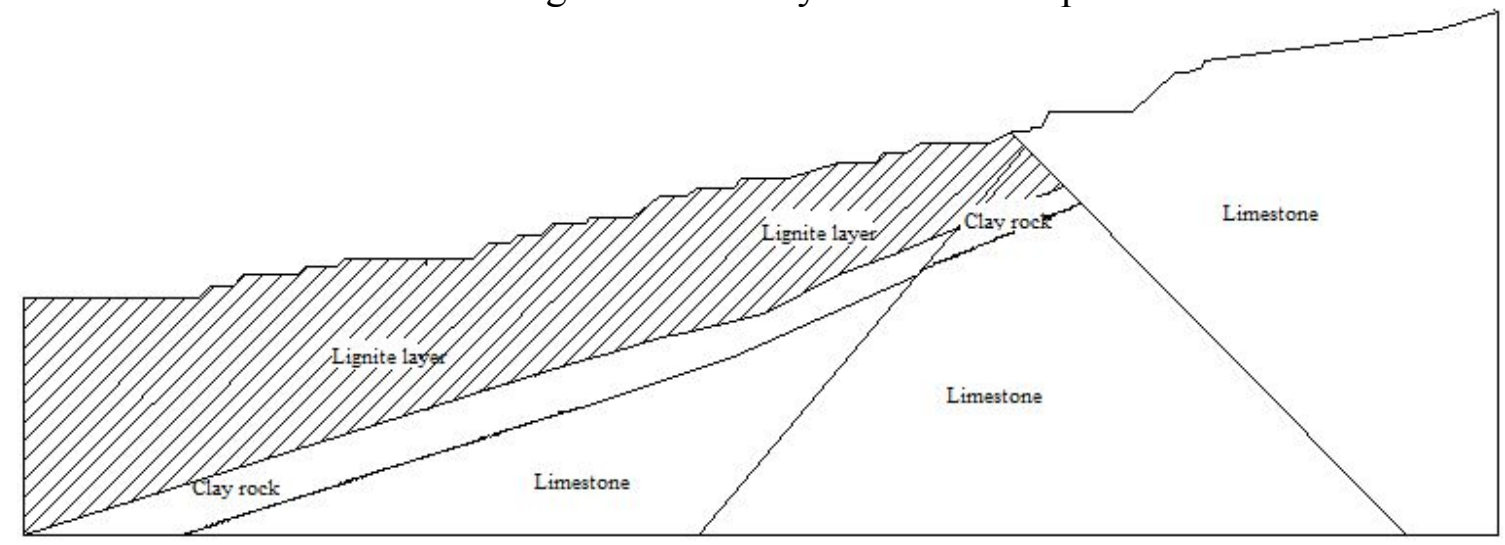

Fig. 2 Slope contour line and rock layer distribution on the 342 section 
Table 1 Geotechnical layer mechanical parameter

\begin{tabular}{|c|c|c|c|c|c|c|}
\hline \multirow{2}{*}{$\begin{array}{c}\text { Rock and } \\
\text { soil layers } \\
\text { name }\end{array}$} & \multicolumn{3}{|c|}{$\begin{array}{c}\text { Mechanical parameters under natural } \\
\text { conditions }\end{array}$} & \multicolumn{2}{|c|}{$\begin{array}{c}\text { Mechanical parameters under } \\
\text { saturated conditions }\end{array}$} \\
\cline { 2 - 7 } & $\begin{array}{c}\text { weight-specif } \\
\text { ic density } \\
(\mathrm{kN} / \mathrm{m} 3)\end{array}$ & $\begin{array}{c}\text { Cohesion } \\
\mathrm{C}(\mathrm{kPa})\end{array}$ & $\begin{array}{c}\text { Internal } \\
\text { friction } \\
\text { angle } \\
\varphi\left(^{\circ}\right)\end{array}$ & $\begin{array}{c}\text { Saturated } \\
\text { unit } \\
\text { weight } \\
(\mathrm{kN} / \mathrm{m} 3)\end{array}$ & $\begin{array}{c}\text { Cohesion } \\
\mathrm{C}(\mathrm{kPa})\end{array}$ & $\begin{array}{c}\text { Internal } \\
\text { friction } \\
\text { angle } \\
\varphi\left({ }^{\circ}\right)\end{array}$ \\
\hline Lignite layer & 20.5 & 18.9 & 9.2 & 11 & 5 & 8.5 \\
\hline Limestone & 22.4 & 210.4 & 22.65 & 22.4 & 110.4 & 19.09 \\
\hline Clay rock & 20.5 & 31 & 12.83 & 11 & 18 & 10 \\
\hline
\end{tabular}

\subsection{Stability Analysis of the Final Slope on the 342 Section}

As shown in Fig. 2, it will appear suspended structure after mining. According to relevant standard and practical engineering experience, it must not exist suspended structure in practical engineering, because the suspended structure easily cause the slide of the rock and soil, which can influence safe production and cause casualties, so it is necessary to govern the 342 section. It adopts the open pit method to the downward mining, take 20 meters as a layer dividing into 19 layers. Since it will forms different slope height and slope toe in the process of exploiting, if adopting the way of exploiting a layer then searching a sliding surface and carrying on a treatment at once not only waste resources and time also is bad for the overall stability of the slope., This paper firstly determines the boundary slope height and slope toe to find a rational treatment scheme. Then, based on this scheme, constructing while mining not only ensures the stability of final slope also ensure the stability of the slope formed during the process of extending downward.

\subsection{Treatment Scheme and Optimization Design of the Final Slope on the 342 Section}

\subsubsection{Treatment Scheme}

According to the engineering situation, this paper proposes three primary design schemesstripping control, coal and gravel pressure foot treatment and prestressed anchor cable treatment.

For stripping treatment scheme, as shown in Fig.3, the coal seam and surface clay layers are stripped in a parallel mining way to meet the load shedding demand, the total stripped amount is $11984400 \mathrm{~m}^{3}$. For coal seams and gravel presser foot treatment scheme, as shown in Fig. 4, it use the reserved coal seam to press foot to reach the basic stability of slope, and through the mullock presser foot to further improve slope stability and ultimately ensure slope safety. The total stripped amount is $878000 \mathrm{~m}^{3}$, the total loss in coal mining output is $14800000 \mathrm{~m}^{3}$ and the quantity of mullock presser foot is $3280000 \mathrm{~m}^{3}$. Analyze its stability after the implementation of the treatment scheme, Fig. 5 and Fig. 6 show the most dangerous landslide slip surface. The result of stability evaluation is shown in Table 2 .

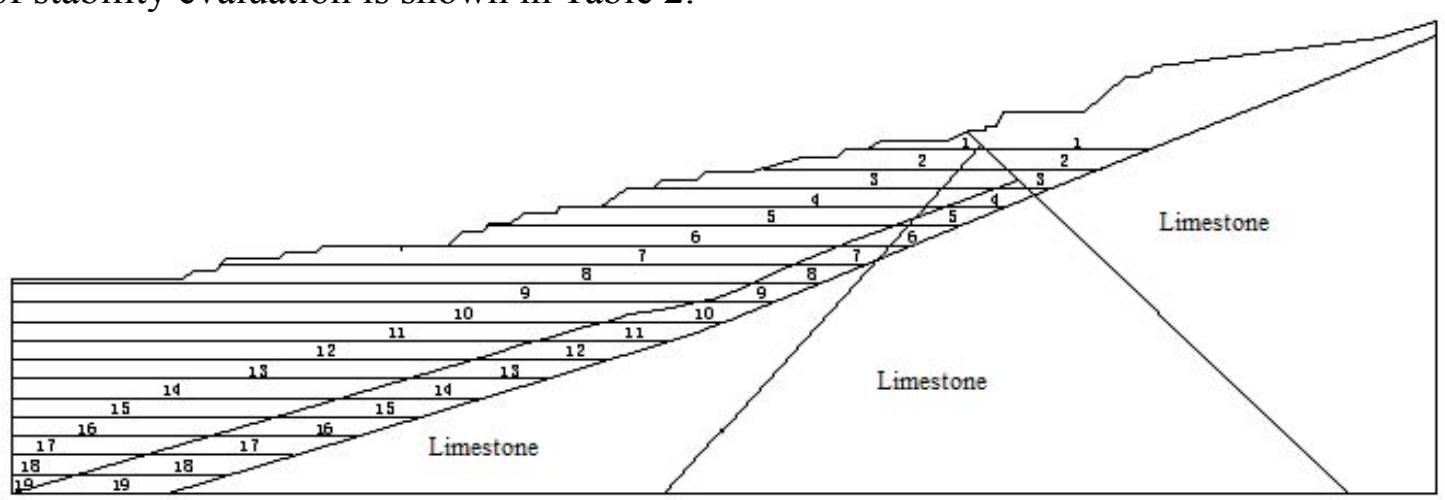

Fig.3 Strip treatment schematic 


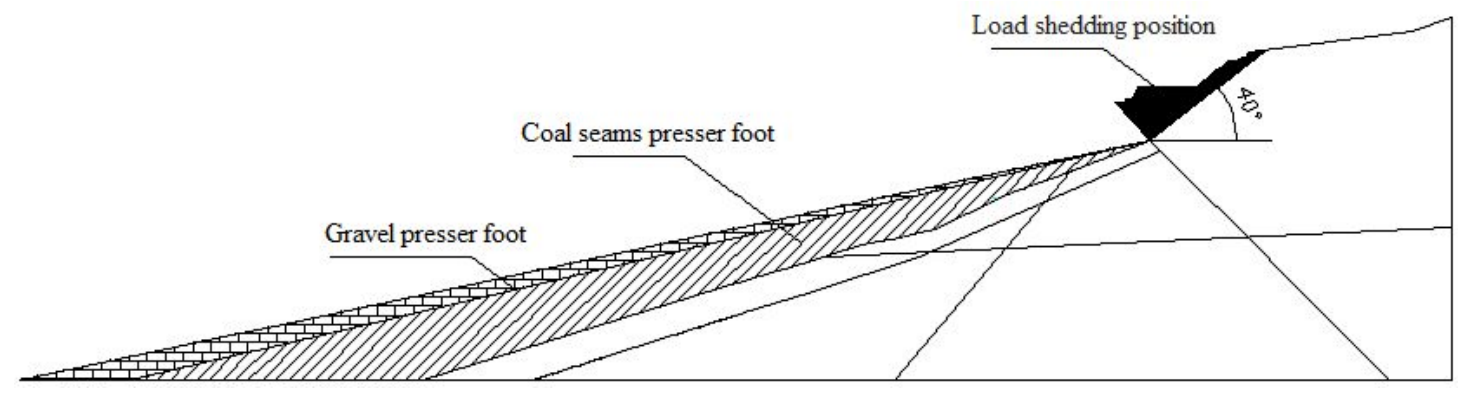

Fig. 4 Presser foot treatment schematic

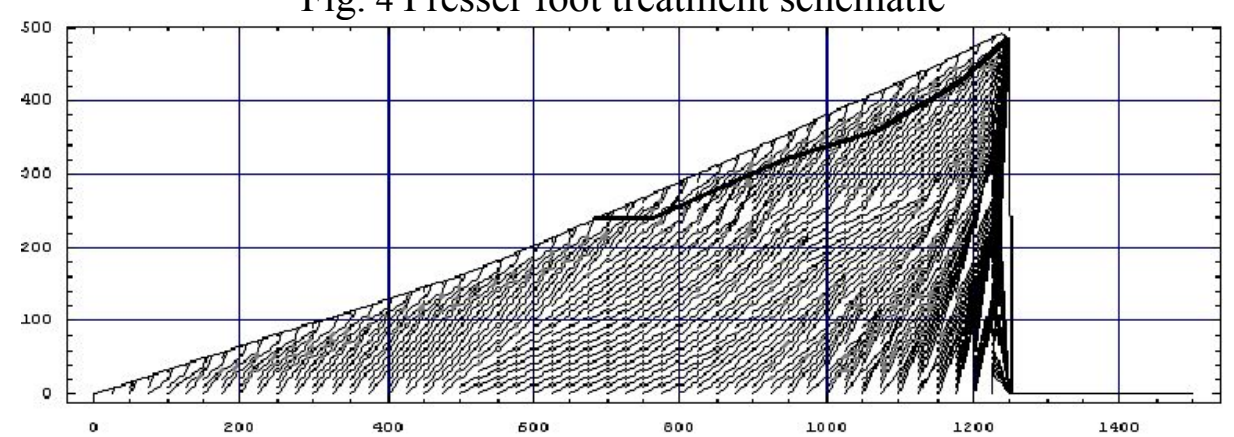

Fig. 5 Dangerous slip surface locations after stripping treatment

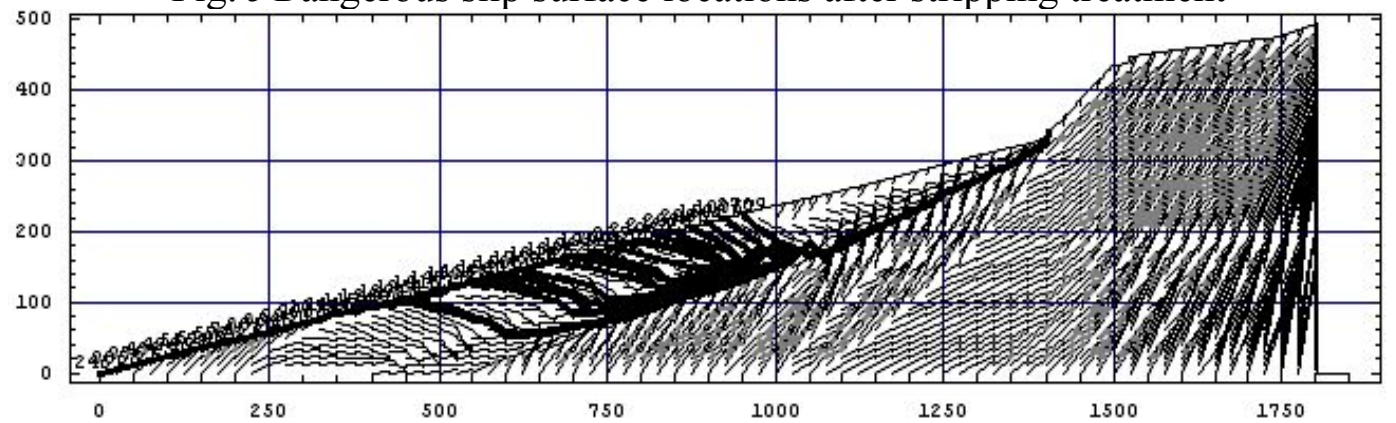

Fig. 6 Dangerous slip surface locations after presser foot treatment

Table 2 Slope stability factor after stripping treatment and presser foot treatment

\begin{tabular}{|c|c|c|c|c|c|}
\hline Calculation method & Ordinary & Bishop & Janbu & Morgenstern-Price & Mean \\
\hline $\begin{array}{c}\text { Slope stability factor after } \\
\text { stripping treatment }\end{array}$ & 1.112 & 1.278 & 1.184 & 1.258 & 1.222 \\
\hline $\begin{array}{c}\text { Slope stability factor after } \\
\text { presser foot treatment }\end{array}$ & 1.156 & 1.223 & 1.143 & 1.341 & 1.216 \\
\hline
\end{tabular}

For prestressed anchor cable treatment scheme, it not only can maximize the open mining quantity also minimize the stripping amount. Moreover, through the holes in advance we can further understand the slope's engineering geological conditions. First, along with the mining, the suspended structure was stripped, the total stripped amount is $878000 \mathrm{~m}^{3}$, then by analyzing the final slope stability, it find that the final slope is in critical state and it will produce landslide. Fig. 7 shows the most dangerous landslide slip surface, the result of stability evaluation is shown in Table 3. The safety factor $\left(\mathrm{F}_{s}\right)$ take 1.2 , the residual thrust of the dangerous sliding body is calculated through transfer coefficient method, Eq. (2) is the residual thrust formula. The case of strip compartmentalization is shown in Fig. 8. Finally, the residual thrust line is achieved, as shown in Fig. 9.

$$
P_{i}=\left(W_{i} \sin \alpha_{i}+K_{0} W_{i} \cos \alpha_{i}\right)-\frac{1}{F_{g}}\left[\left(W_{i} \cos \alpha_{i}-K_{0} W_{i} \sin \alpha_{i}\right) \tan \varphi_{i}+c_{i} l_{i}\right]+\Psi_{i} P_{i-1}
$$


$\Psi_{i}$ is the surplus sliding force transfer coefficient, $\Psi_{i}=\cos \left(\alpha_{i-1}-\alpha_{i}\right)-\sin \left(\alpha_{i-1}-\alpha_{i}\right) \frac{\tan \varphi_{i}}{F_{g}}$, the meaning of other symbols as described earlier.

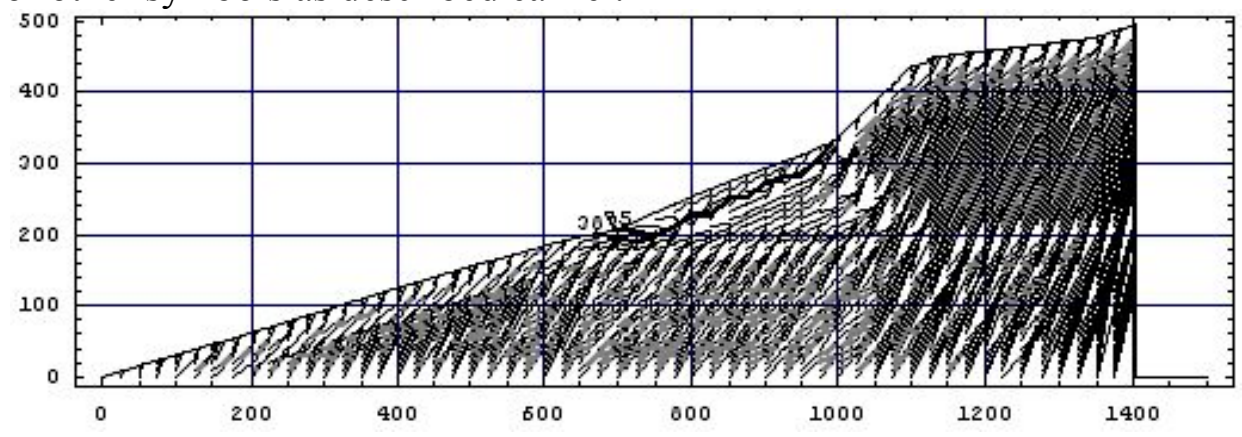

Fig. 7 Dangerous slip surface locations of the final slope

Table 3 Slope stability factor of the final slope

\begin{tabular}{|l|c|c|c|c|c|}
\hline Calculation method & Ordinary & Bishop & Janbu & Morgenstern-Price & Mean \\
\hline Slope stability factor & 0.864 & 0.929 & 0.915 & 0.983 & 0.923 \\
\hline
\end{tabular}

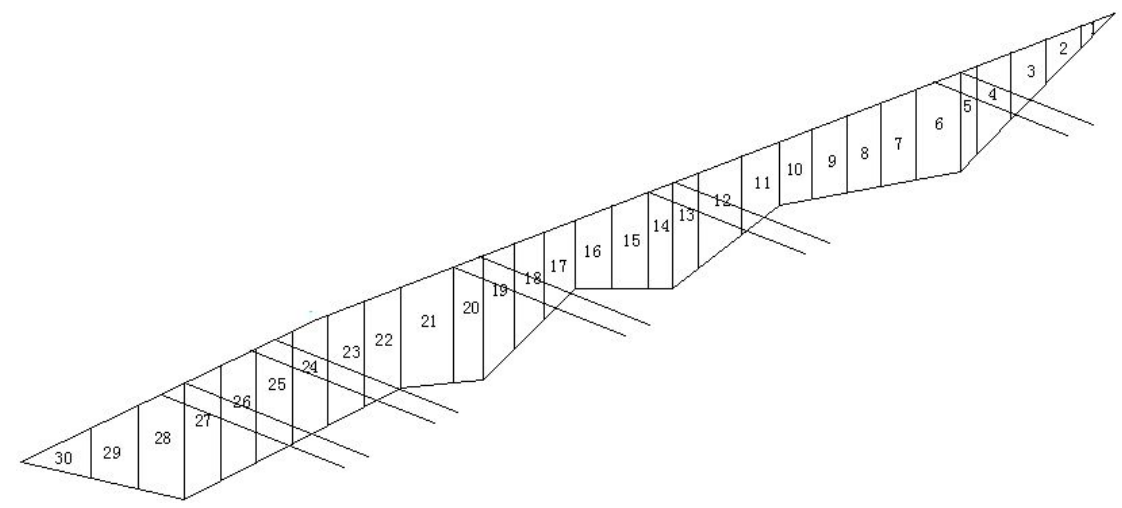

Fig. 8 Strip compartmentalization and anchor position arrangement

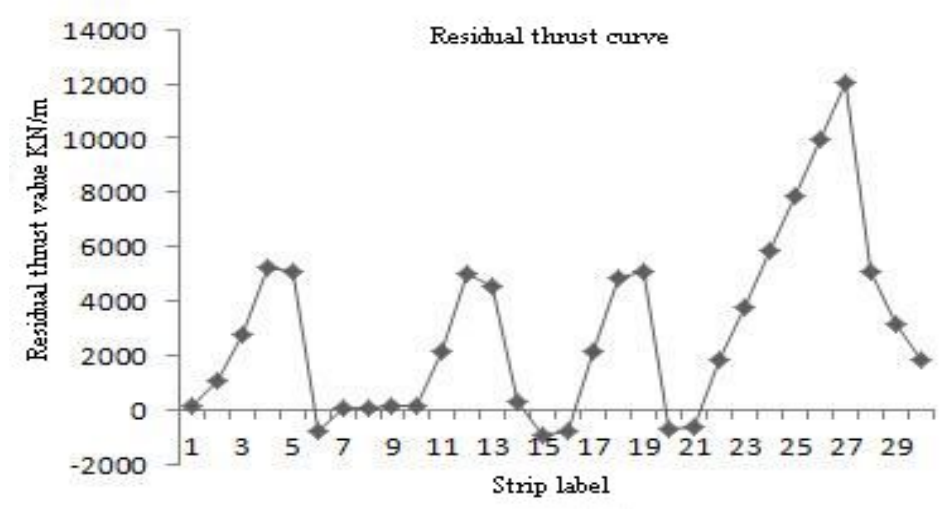

Fig. 9 Primitive residual thrust curve

Combining with the residual thrust curve shown in Fig. 9 and basing on the formula: $\beta=\alpha \pm\left(45^{\circ}+\frac{\varphi}{2}\right), \beta=\frac{45^{\circ}}{A+1}+\frac{2 A+1}{2(A+1)} \varphi-\alpha$ choose the anchorage angle $(\beta)$ is 30 degrees. In order to ensure the uniform distribution of the value of the residual thrust in the middle of each strip, avoid too big peak, prevent the occurrence of damage, ensure that the value of the residual thrust in the last strip is less than zero and last ensure the overall stability of the slope, 
through a series of analysis, we finally determine the anchor position arrangement as shown in Fig. 8: a group of two, divided into five groups, each anchor longitudinal spacing are $4 \mathrm{~m}$ and connected with the frame ground beams, each anchorage force $P_{t}=\frac{4 \times 1900}{10}=760 \mathrm{kN}$, the design value take $800 \mathrm{kN}$. Fig. 10 shows the residual thrust curve after the anchor reinforcement. Compared with Fig. 10 and Fig. 9, it can conclude that the peak of the residual thrust value decreased significantly, the value of the residual thrust in the last strip is less than zero and the dangerous sliding body is in a stable state.

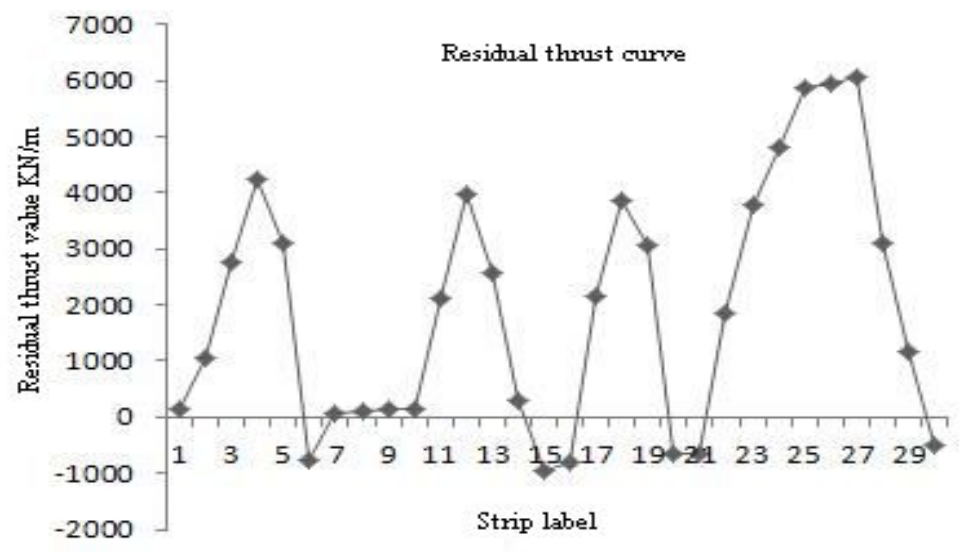

Fig.10 Ultimate residual thrust curve

The strength and length of the anchor cable is designed, and the final result is that: single-hole anchor cable choose 7 standard steel strand whose nominal diameter is $11.25 \mathrm{~mm}$, the circular hole diameter is $0.12 \mathrm{~m}$, the grouting material choose M25 type cement mortar, the first group anchor cable minimum length $=$ anchorage length + free length + tensioning length $=7+18+1.2=$ $22.5 \mathrm{~m}$, the second and third anchor cable minimum length $=$ anchorage length + free length + tensioning length $=7+22+1.2=30.5 \mathrm{~m}$, The fourth and fifth group anchor cable minimum length $=$ anchorage length + free length + tensioning length $=7+27+1.2=31.5 \mathrm{~m}$. Based on the length, the detailed anchor cable design process and concrete frame beam design is no longer described one by one. By analyzing the stability of the slope after reinforcement, it find that after reinforcement the slope is in steady state, the result of stability evaluation is shown in Table 4.

Table 4 Slope stability factor after prestressed anchor cable treatment

\begin{tabular}{|l|c|c|c|c|c|}
\hline Calculation method & Ordinary & Bishop & Janbu & Morgenstern-Price & Mean \\
\hline Slope stability factor & 1.164 & 1.229 & 1.215 & 1.283 & 1.223 \\
\hline
\end{tabular}

\subsubsection{Cost Analysis of Slope Treatment Scheme}

Using the Integrated unit price method to analyze the cost of every treatment scheme, and finally come to the comparison table of the cost of every treatment scheme, as shown in Table 5.

Table 5 Cost analysis of slope treatment scheme (unit: ten thousand yuan)

\begin{tabular}{|c|c|c|c|c|c|c|}
\hline Cost & $\begin{array}{c}\text { Load } \\
\text { shedding } \\
\text { costs }\end{array}$ & Freight & $\begin{array}{c}\text { Presser foot } \\
\text { costs }\end{array}$ & $\begin{array}{c}\text { Anchor } \\
\text { cable costs }\end{array}$ & $\begin{array}{c}\text { Frame } \\
\text { beam } \\
\text { costs }\end{array}$ & Total \\
\hline $\begin{array}{c}\text { Stripping treatment } \\
\text { scheme }\end{array}$ & 28093.1 & 10722.1 & 0 & 0 & 0 & 38815.2 \\
\hline $\begin{array}{c}\text { Presser foot } \\
\text { treatment scheme }\end{array}$ & 2058.91 & 0 & 41.75 & 0 & 0 & 2100.66 \\
\hline $\begin{array}{c}\text { Prestressed anchor } \\
\text { cable treatment } \\
\text { scheme }\end{array}$ & 2058.91 & 785.81 & 0 & 480 & 55.23 & 3379.95 \\
\hline
\end{tabular}




\subsubsection{Determination of Slope Treatment Scheme}

From Table 5 and the description of the various treatment schemes, for stripping treatment scheme, although it can make the coal mining output maximum on the premise of ensuring the stability of the slope, the stripping quantity also is large, and it need to transport large amounts of mullock to outside, which extends the time of the project and enhances the cost; For coal seams and gravel presser foot treatment scheme, it combine the coal seam presser foot and gravel presser foot, which not only reduce the required stripping quantity also save the transport costs and the Stacking cost, it has a dual economic benefit, but it also contributes to the reduction of the coal mining output, this plan is not ideal, in the case of the large demand of coal. For prestressed anchor cable treatment scheme, it adopts prestressed anchor cable for active anti slip control on the premise of ensuring the stability of the slope, it not only make the coal mining output maximum also stripping quantity minimum thus greatly reducing the project cost. So considering the degree of difficulty of project implementation, applicability and economy advises the final slope on the west side 342 section adapts the prestressed anchor cable treatment scheme.

\section{Summary}

Based on the critical slip field technique, the most dangerous sliding surface is determined and then critical slope stability is analyzed though various limit equilibrium methods, which combines the rational point of each method, can obviously improve the accuracy of analysis results and provide a powerful scientific guarantee to achieve both safe and reliable and practical slope optimization design. Through the systematic slope stability analysis and the optimization design research, it can conclude that for the final slope on the 342 section, the prestressed anchor cable treatment scheme is the optimal selection.

\section{Acknowledgments}

The First Author: ShiguoSun (1959- ), male,Postdoctoral. The professor of the northern industrial university majoring in civil engineering construction engineering college level discipline responsibility, doctoral supervisor. Mine safety and the northern industrial university institute of geotechnical engineering.

Fund Project: This research has been funded by The National Natural Science Foundation of China

(No.41172250), National five-year science and technology support project (2012BAK09B06), The innovative team project of Beijing (IDHT20140501), The scientific research base construction, scientific research innovation platform, scientific research and special - impact pressure build of microseismic monitoring and early warning system (XN083) and New type of anchor reinforcement technique field test research and graduate student ability training (XN107).

\section{References}

[1]Yinghui Cui, Shiguo Sun. The application of critical slip field method in Bu-Zhao- Ba open-pit slope, J. Morden Mining. Vol. 5 (2010), p. 67-69.

[2]Dayong Zhu, Zaosheng Zhou. Global slope critical slip field (GCSF) theory and engineering application, J. China Civil Engineering Journal. Vol. 32(1999), p.66-72.

[3]Dayong Zhu, Qihu Qian, Zaosheng Zhou,etc. Slope critical sliding field based on the residual thrust method, J. Chinese Journal of Rock Mechanics and Engineering. Vol. 18(1999), p.667-670. 